\title{
Studying Musical Savants: A Commentary on Grundy and Ockelford
}

\author{
BÉNÉDICTE POULIN-CHARRONNAT[1] \\ CNRS, Université de Bourgogne
}

\begin{abstract}
On the basis of the "zygonic" theory of musical understanding (Ockelford, 2006), Grundy and Ockelford (2014) investigated musical expectations evoked during the course of hearing a piece for the first time in a prodigious musical savant (Derek Paravicini). Overall, the results provided by Derek support the principles of the zygonic theory, especially that the higher the implication factor of a note, the more likely Derek would predict its occurrence. In my commentary, I first raise the question of the use of such individuals as musical savants to generalize findings to the general population, and second I address the issue of the task and the stimuli used.
\end{abstract}

Submitted 2014 January 27; accepted 2014 February 6.

KEYWORDS: zygonic theory, musical expectation, musical savant

ON the basis of "zygonic" theory (Ockelford, 2006), Grundy and Ockelford (2014) investigated musical expectations evoked during the hearing of a piece for the first time in a prodigious musical savant (Derek Paravicini). Overall, the results provided by Derek support the principles of zygonic theory, especially that the higher the implication factor of a note, the more likely Derek would predict its occurrence.

\section{GENERALISATION FROM MUSICAL SAVANTS TO THE GENERAL POPULATION}

One of the objectives of Grundy and Ockelford's study was "to test the theory that a listener's strength of expectation increases with the number of implicative zygonic relationships that musical analysis suggests are present" (p. 53). After having discussed the limits of some experimental methods, such as subjective evaluation of musical continuations or continuation production, they proposed to test a musical savant, Derek Paravicini. As acknowledged by the authors, "it could be argued that data acquired from a savant such as Derek are of limited value in understanding human musicality in a general sense, since he is, by definition, atypical." Derek has autism, he is totally blind, he has absolute pitch and he is internationally acknowledged for his exceptional musical abilities. According to Rimland (1988), within the general population, savants number only one in 20,000. In addition, there is evidence that blind individuals have more efficient auditory perceptual processing than sighted individuals. Derek seems to be light years away from the "normal" listener. Admittedly, his results are in line with zygonic theory, however, to say "Data gathered from Derek's performance support the underlying principles of the zygonic model" (Grundy \& Ockelford, 2014, abstract) is probably too strong. Such a case study cannot prove zygonic theory.

To validate the principle of the zygonic theory, a large population of non-savant listeners, both musicians and non-musicians, should support its principles. It has been suggested that non-musician listeners, through passive exposure to music and implicit learning mechanisms, internalize the regularities present in the musical system with which they are familiar. Such implicit learning leads them to perceive musical structure as musicians do (for a review see Bigand \& Poulin-Charronnat, 2006).

As suggested by the authors, "the analysis of the music that savants produce in response to musical stimuli can offer a unique insight into the 'black box' of their mental processing" (2014, p. 54). However, the production of musical savants alone cannot be used to prove the zygonic theory, as this must initially be validated in non-savants, musicians but also non-musicians, who are the most representative listeners in the general population. 


\section{TASK AND MUSICAL STIMULI}

Because the authors focus on between-group expectations evoked on hearing a musical piece for the first time, the musical piece they created "was designed to minimize the impact of expectations that may arise from patterns within groups of notes and those that may be perceived as a consequence of tonality" (2014, abstract). By doing so, and even if the authors want to see what impact repeated appearances of the same motif have on what a listener anticipates, they finally created a very repetitive musical piece, which is not ecologically valid. With certain minor exceptions, most existing musical works are not so redundant. In addition, when $\# Z$, which represents the number of relationships (necessarily zygonic), is equal to 14 the zygonic theory predicts a ceiling effect (this effect appears when $\# Z \geq 8$ in Derek's performance). In that case, creating a musical piece at the end of which $\mathrm{AZ}$ could be equal to 31 , does not seem to be necessary.

The authors used a "playing along" task, in which Derek has to "shadow" a new musical piece. The authors acknowledge that "complex though this approach may be, listening, learning and playing all at the same time constitute a form of multitasking that comes naturally to Derek." (2014, p. 55). Although, this complex task comes naturally to Derek, it is certainly not the case for non-savant people.

In order to test the zygonic theory with non-savant people, the authors must return to experimental paradigms such as continuation ratings, continuation production, or priming. All these paradigms have been adapted in the past to assess expectations in music (see Tillmann, Poulin-Charronnat, \& Bigand, 2014, for a review). The authors say that "since the focus is on between-group expectations that may arise in the first hearing of a piece, a multiplicity of short passages would need to be constructed in order to test a listener's reaction to implications involving different numbers of motifs." This is true, although creating test material in such a way is common practice in experimental psychology. Furthermore, the authors add that "to avoid possible interference, these would need to be contrasting, yet also share an underlying equivalence in terms of cognitive processing demanded by each implicative relationship - a difficult (if not impossible) circle to square in music-compositional terms". Creating different musical pieces, where the tested notes should have different $\# Z$, does not appear to be impossible.

\section{CONCLUSIONS}

The principles of the zygonic theory should first be evaluated with non-savant people, both musicians and non-musicians, to address how the non-savant population perceives different kinds of expectations according to their degree of implication. Adapted paradigms and tasks must be used. Once these principles have been supported in the non-savant population, then testing savant individuals may teach us more on how their brains work and how their cognitive functions differ from non-savant individuals.

\section{REFERENCES}

Bigand, E. \& Poulin-Charronnat, B. (2006). Are we "experienced listeners"? A review of the musical capacities that do not depend on formal musical training. Cognition, 100(1), 100-130.

Ockelford, A. (2006). Implication and expectation in music: A zygonic model. Psychology of Music, 34(1), 81-142.

Grundy, R. \& Ockelford, A. (2014). Expectations evoked on hearing a piece of music for the first time: Evidence from a musical savant. Empirical Musicology Review, 9(2), 47-98.

Rimland, B. (1988). Special talents of autistic savants. In L. Obler \& D. Fein (Eds.), The exceptional brain: Neuropsychology of talent and special abilities (pp. 474- 492). New York: Guilford Press.

Tillmann, B., Poulin-Charronnat, B., \& Bigand, E. (2014). The role of expectation in music: From the score to emotions and the brain. WIRES Cognitive Science, 5(1), 105- 113. 


\section{NOTES}

[1] Correspondence for this commentary can be addressed to: Bénédicte Poulin-Charronnat, Université de Bourgogne, LEAD - CNRS UMR5022, Pôle AAFE, 11 Esplanade Erasme, 21000 Dijon. E-mail: benedicte.poulin@u-bourgogne.fr. 